\title{
Range of Movement for Impingement and Dislocation Avoidance in Total Hip Replacement Predicted by Finite Element Model
}

\author{
Laura Ezquerra ${ }^{1,3} \cdot$ María Paz Quilez $^{2}$ - María Ángeles Pérez ${ }^{2}$. \\ Jorge Albareda $^{1} \cdot$ Belén Seral $^{1}$
}

Received: 4 January 2016/ Accepted: 18 May 2016/Published online: 21 January 2017

(C) Taiwanese Society of Biomedical Engineering 2017

\begin{abstract}
Dislocation is a serious complication in total hip replacement (THR). An inadequate range of movement (ROM) can lead to impingement of the prosthesis neck on the acetabular cup; furthermore, the initiation of subluxation and dislocation may occur. The objective of this study was to generate a parametric three-dimensional finite element (FE) model capable of predicting the dislocation stability for various positions of the prosthetic head, neck, and cup under various activities. Three femoral head sizes $(28,32$, and $36 \mathrm{~mm})$ were simulated. Nine acetabular placement positions (abduction angles of $25^{\circ}, 40^{\circ}$ and $60^{\circ}$ combined with anteversion angles of $0^{\circ}, 15^{\circ}$ and $25^{\circ}$ ) were analyzed. The ROM and maximum resisting moment (RM) until dislocation were evaluated based on the stress distribution in the acetabulum component. The analysis allowed for the definition of a "safe zone" of movement for impingement and dislocation avoidance in THR: an abduction angle of $40^{\circ}-60^{\circ}$ and anteversion angle of $15^{\circ}-$ $25^{\circ}$. It is especially critical that the anteversion angle does not fall to $10^{\circ}-15^{\circ}$. The sequence of the RM is a valid parameter for describing dislocation stability in FE studies.
\end{abstract}

Keywords Safe zone - Impingement - Dislocation · Finite element analysis $\cdot$ Resisting moment

Laura Ezquerra

ezqlaura@gmail.com

1 Department of Orthopaedic Surgery, University Hospital Lozano Blesa, San Juan Bosco, 15, 50009 Saragossa, Spain

2 Aragón Institute of Engineering Research (I3A), University of Zaragoza, Maria de Luna s/n, Campus Río Ebro, Edificio "Agustín de Betancourt", 50018 Saragossa, Spain

3 C/El Greco, 150, Urbanización Virgen de la Columna, 50730 El Burgo de Ebro, Saragossa, Spain

\section{Introduction}

Dislocation is a severe complication in total hip replacement (THR). Its probability ranges from 0.3 to $10 \%$ in primary THR and up to $28 \%$ in cases of revision $[1,2]$.

The etiology of prosthetic dislocation is multifactorial $[3,4]$ : the most common risk factors include surgical approach, diagnosis that determines the arthroplasty, surgical technique, arthroplasty life time, and patient's general condition.

Malpositioning of the implant component causes approximately $30-40 \%$ of all dislocations [5]. The range of movement (ROM) depends on the position and design of the implant [6]. Excessive joint motion can lead to impingement of the femoral neck on the acetabular cup and can induce dislocation. Moreover, recurrent impingement can cause material failure of the implant components, such as excessive wear of polyethylene liners. These failures occur as a result of high localized contact stress at the impingement site $[7,8]$.

To evaluate the dislocation stability of different implant designs, various experimental studies have been conducted [9-12], along with studies based on the finite element method (FEM) [8, 13-19]. In conventional-sized THR, impingement typically occurs between the implant femoral neck and acetabular cup. Therefore, the vast majority of experimental/computational studies of THR impingement and ROM have used THR components tested/simulated in isolation.

Bader et al. [9] developed an experimental testing device to analyze the ROM in THR as well as, the RM during dislocation and stability against dislocation. Burroughs et al. [10] performed an in vitro study to evaluate the effect of larger head sizes on the type of impingement, ROM and joint stability. The authors concluded that large 
femoral heads provide a greater ROM and eliminate component-to-component impingement. Matsushita et al. [11] quantified the effect of femoral offset and head size on ROM, obtaining conclusions similar to those of Burroughs et al. [10].

Scifert et al. [17] highlighted the relationship between the RM and dislocation. The authors analyzed a large series of implant designs with regard to posterior dislocation. Nadzadi et al. [8] emphasized the importance of anterior dislocation for different acetabular component orientations but only for small-head-size THR. Pedersen et al. [16] also used a small head size to examine the relationship between impingement and dislocation for various motion challenges. Kluess et al. [15] demonstrated that an optimal implant position and a larger head diameter can reduce the risk of impingement-induced dislocation.

The increasing capability and versatility of finite element (FE) modeling have opened up new possibilities for studying mechanical interactions among component-related design factors and their influence on dislocation. Previous computational studies have not considered the versatility of developing a parameterized geometry of THR. Additionally, only limited ranges of the anteversion angle have been studied previously, and thus, any impingement that occurs when the patient is in a seated position has not been observed. Therefore, the objective of the present study was to generate a simplified threedimensional (3D) parametric FE model capable of predicting the dislocation stability for various positions and for various designs of the prosthetic head, neck and cup. A "safe zone" for flexion and extension movements with respect to impingement and dislocation was investigated over a wide range of parameter values. It is hypothesized that a simple parametric model may help to advise clinicians about the most adequate positions for avoiding dislocation.

\section{Methods}

\subsection{Geometric and Finite Element Models}

The geometry and dimensions of the implant were obtained from a standard 37.5- mm-offset Exeter ${ }^{\circledR}$ cemented prosthesis [20] with a collarless, smooth, polished, tapered stem positioned in an anatomical neutral orientation of $0^{\circ}$ version. Any other implant model can be easily simulated. Three femoral head sizes were simulated: 28, 32, and $36 \mathrm{~mm}$ in diameter. The outer acetabulum component diameter was considered as $52 \mathrm{~mm}$ for all femoral head sizes. The parametric geometrical model was developed in Abaqus CAE v6.11 and consisted of two parts. The acetabulum component was modeled as a deformable solid from a surface of revolution. The femoral head and the stem were modeled as a discrete rigid shell through a surface of revolution and an extruded surface, respectively. Additionally, a round edge was considered for the stem (Fig. 1). The femoral head and stem were modeled as rigid surfaces instead of being approximately modeled using a deformable body due to the significant difference in structural stiffness between the metal components (femoral head and stem) and the polyethylene liner of the acetabulum component. Thus, the deformation of the femoral head and stem can be neglected. Bone and soft tissues were not considered in the simulation. The FE mesh of the model with a 28-mm head size consisted of 10164 hexahedral elements (C3D8R) for the acetabulum component and 2900 triangular and quadrilateral elements (R3D3 and R3D4, respectively) for the stem and head. A sensitivity analysis was performed to choose the most adequate element size for the FE mesh. We studied three element sizes (1, 1.5, and $2 \mathrm{~mm}$ ). The computation times were 120, 18, and $5 \mathrm{~min}$, respectively, for a computational cluster with 224 cores and $575 \mathrm{~GB}$ of RAM. The results for 1 and $1.5 \mathrm{~mm}$ were almost equal in terms of precision, whereas those obtained using $2 \mathrm{~mm}$ were less precise. The selected element size (approximately $1.5 \mathrm{~mm}$ ) is within the asymptotic region of convergence and is a good trade-off between numerical accuracy and computational cost.
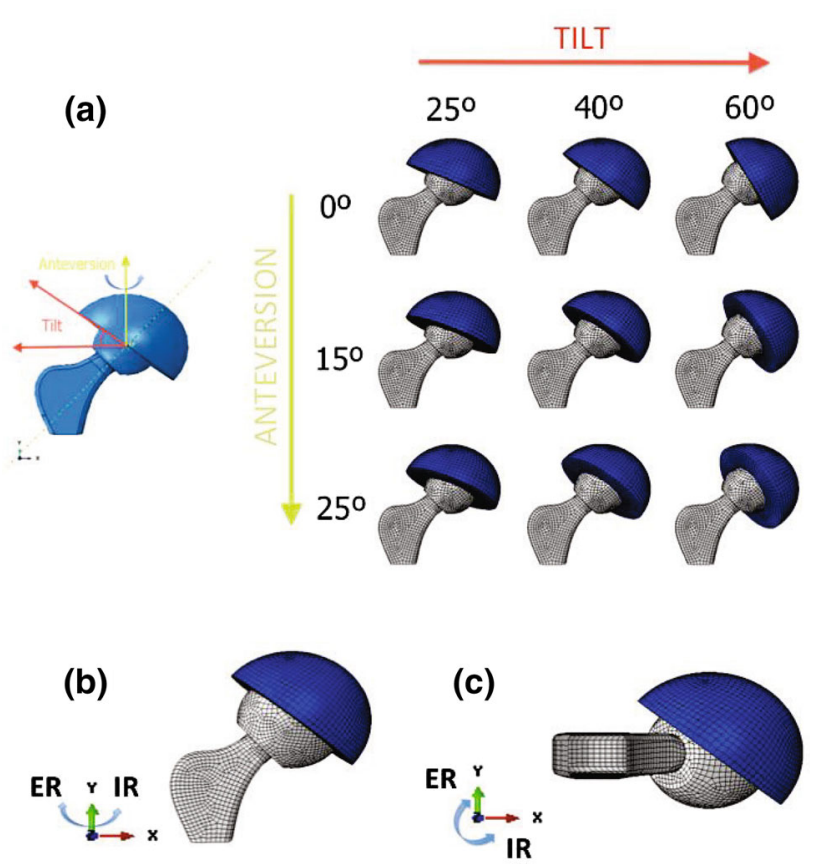

Fig. $13 \mathrm{D}$ prosthesis models with coordinate axes. a Simulated positions $\left(0^{\circ}, 15^{\circ}\right.$ and $25^{\circ}$ anteversion and $25^{\circ}, 40^{\circ}$, and $60^{\circ}$ tilt $)$ and rotations (internal, IR, and external, ER) under b extension and c flexion 
Therefore, the remaining FE models contain similar numbers of nodes and elements.

For the three femoral head sizes, different positions of the acetabulum component (cup orientation) with respect to the femoral head were analyzed to study component impingement and dislocation. Nine acetabular placement positions (tilt or abduction angles of $25^{\circ}, 40^{\circ}$ and $60^{\circ}$ combined with anteversion angles of $0^{\circ}, 15^{\circ}$ and $25^{\circ}$ ) were chosen (Fig. 1). These limits were studied because they are widely accepted. A cup with a tilt of more than $60^{\circ}$ is considered vertical and is predisposed to instability [21]. An anteversion of $>25^{\circ}$ has a high probability of anterior luxation [22]. These positions are based on the radiographic definition of cup orientation [23-25].

\subsection{Material Properties and Nonlinearity of Simulated Problem}

The analyses are highly nonlinear due to large displacements, the nonlinear definition of the material, and the contact between components. The acetabular component was simulated with an ultra-high-molecular-weight polyethylene (UHMWPE) material. An elastic modulus of $\mathrm{E}=940 \mathrm{MPa}$, Poisson's ratio of $v=0.3$, and yield strength of $26.26 \mathrm{MPa}$ were assumed for the acetabulum component material, simulating the plastic properties of polyethylene [15, 26, 27].

Regarding the contact properties, the femoral head and neck were defined as master surfaces and the inner hemisphere of the acetabulum component and outer ring were defined as slave surfaces. Tangentially isotropic mechanical behavior was introduced, with a friction coefficient of $0.038[16,18,19]$.

\subsection{Boundary Conditions and Simulated Movements}

Two types of movement (internal $-40^{\circ}$ - and external $-60^{\circ}$-rotation: physiological endpoints) $[28,29]$ from two different positions (flexion $-90^{\circ}$ - and extension $-0^{\circ}$-were simulated until impingement and dislocation of the components occurred (Fig. 1). These positions represent standing (extension) and seated (flexion) maneuvers with applied rotation. Abduction and adduction were not simulated to avoid an excessively complicated model. The origin of the Cartesian coordinate system used is in the head center of the right leg, the $\mathrm{x}$-axis points medially, the $y$-axis points cranially and the $\mathrm{z}$-axis points anteriorly (Fig. 1). The nodes of the external acetabulum component were fixed to simulate its complete fixation. All rotations were applied with respect to the reference point in the center of the head (Fig. 1).

\subsection{Numerical Characteristics of Simulations}

Numerical singularities in the FE model cause the analysis to abort. Therefore, dislocation was defined by the onset of numerical instability of the contact model.

\section{Results}

The ROM [30] and maximum RM until impingement and dislocation were evaluated for all simulated cases, based on the stress distribution in the acetabulum.

\subsection{Implant Position: Abduction and Anteversion Angles}

The analysis revealed two opposite positions favoring dislocation. For extension and external rotation, there was an early anterior dislocation with the highly anteverted $(\beta)$ and abducted $(\alpha)$ cup position. In contrast, for flexion and internal rotation, there was an early posterior dislocation with the less anteverted $(\beta)$ and less abducted $(\alpha)$ cup position.

A cup position of $40^{\circ}-60^{\circ}$ abduction $(\alpha)$ and $15^{\circ}-25^{\circ}$ anteversion $(\beta)$ was the ideal position for a maximum impingement-free ROM for both modes of dislocation (Fig. 2).

It was observed that as the anteversion was increased, progressively more flexion was achieved before impingement between components occurred. For example, for the $28-\mathrm{mm}$ head, impingement occurred at $79^{\circ}$ of flexion with $0^{\circ}$ cup anteversion, at $86^{\circ}$ of flexion with $15^{\circ}$ cup anteversion, and at $92^{\circ}$ of flexion with $25^{\circ}$ cup anteversion. Thus, with $0^{\circ}-15^{\circ}$ cup anteversion, the hip functionality will be very limited because the patient will not be able to reach a seated position.

The RM analysis indicated an increase in RM with more anteverted cups (Fig. 3) and the same result with abducted cups (Fig. 4) for all head sizes. The smaller the developed RM, the higher the risk of dislocation. Additionally, Fig. 3 shows that for the $28-\mathrm{mm}$ head size with a cup position of $25^{\circ}$ abduction under flexion movement, subluxation occurs after impingement for the three anteversion cup positions. However, in Fig. 4, it can be observed that for 32-mm head size with $25^{\circ}$ anteversion for the cup position in flexion movement, subluxation occurs simultaneously with impingement for the three different tilt cup positions.

\subsection{Head Size}

Increasing the femoral head size led to decreased impingement and dislocation. Accordingly, for the 32- and 
Fig. 2 Maximum impingement-free ROM for both modes of dislocation for 28-mm head size

Fig. 3 Variation of RM for 28-mm head size under flexion movement with cup position of $25^{\circ}$ abduction and $0^{\circ}, 15^{\circ}$ and $25^{\circ}$ anteversion
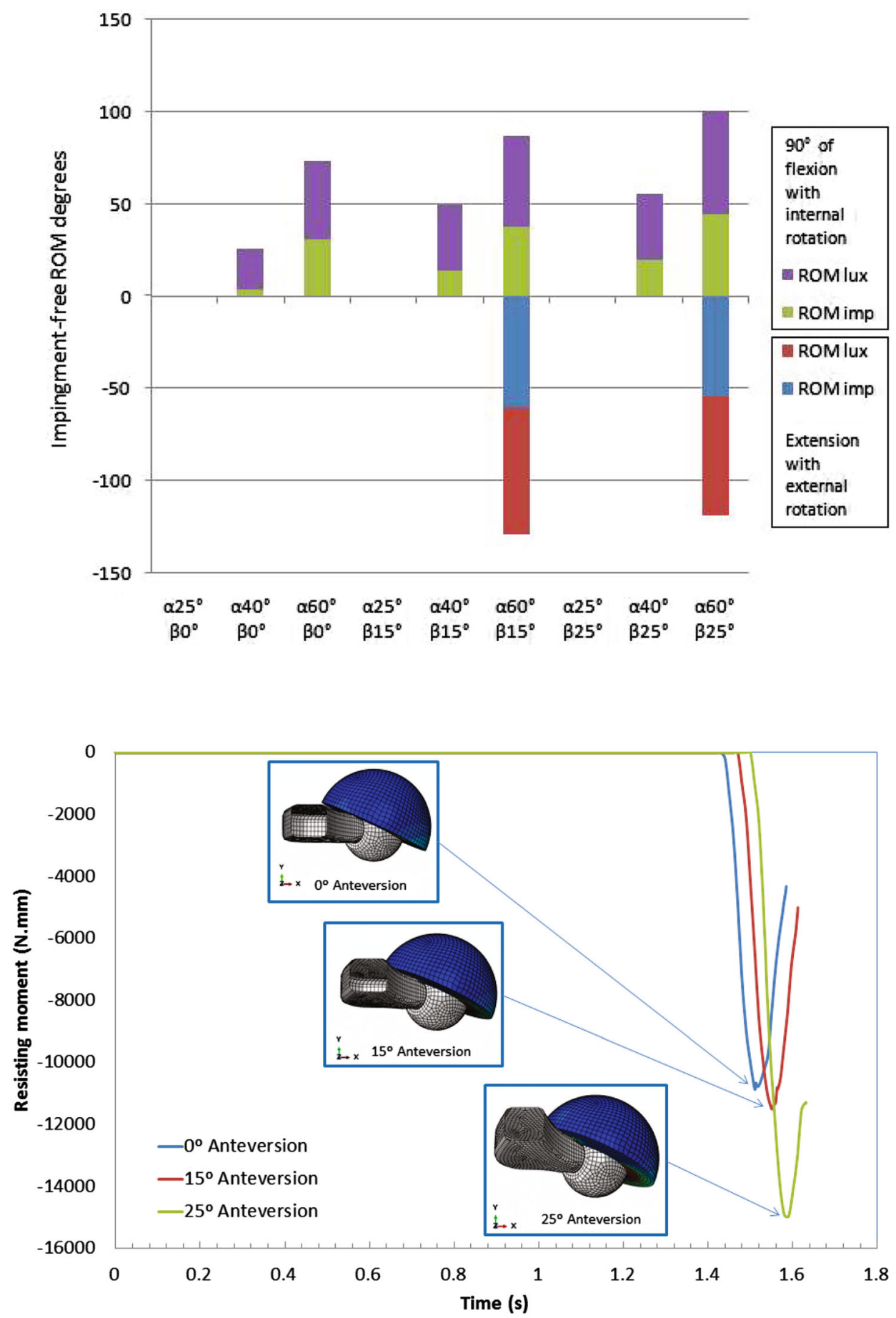

36-mm head sizes, there was no posterior dislocation. The maximum impingement-free ROM was higher for the $36-\mathrm{mm}$ head size compared to those for the 32 -and $28-\mathrm{mm}$ head sizes for a given cup position. For the case of abduction $(\alpha) 40^{\circ}$ and anteversion $(\beta) 0^{\circ}$ with internal rotation, the ROM rose from $4^{\circ}\left(28-\mathrm{mm}\right.$ head size) to $13^{\circ}$ (32-mm head size) (Fig. 5).
The RM also increased for larger femoral head diameters, indicating a smaller risk of dislocation for larger heads (Fig. 6). However, subluxation and impingement occurred simultaneously as the head size increased (Fig. 6).

In all cases during subluxation, the yield stress of UHMW-PE (23.56 MPa) was greatly exceeded at the 
Fig. 4 Variation of RM for 32-mm head size under flexion movement with cup position of $25^{\circ}$ anteversion and $25^{\circ}, 40^{\circ}$ and $60^{\circ}$ abduction

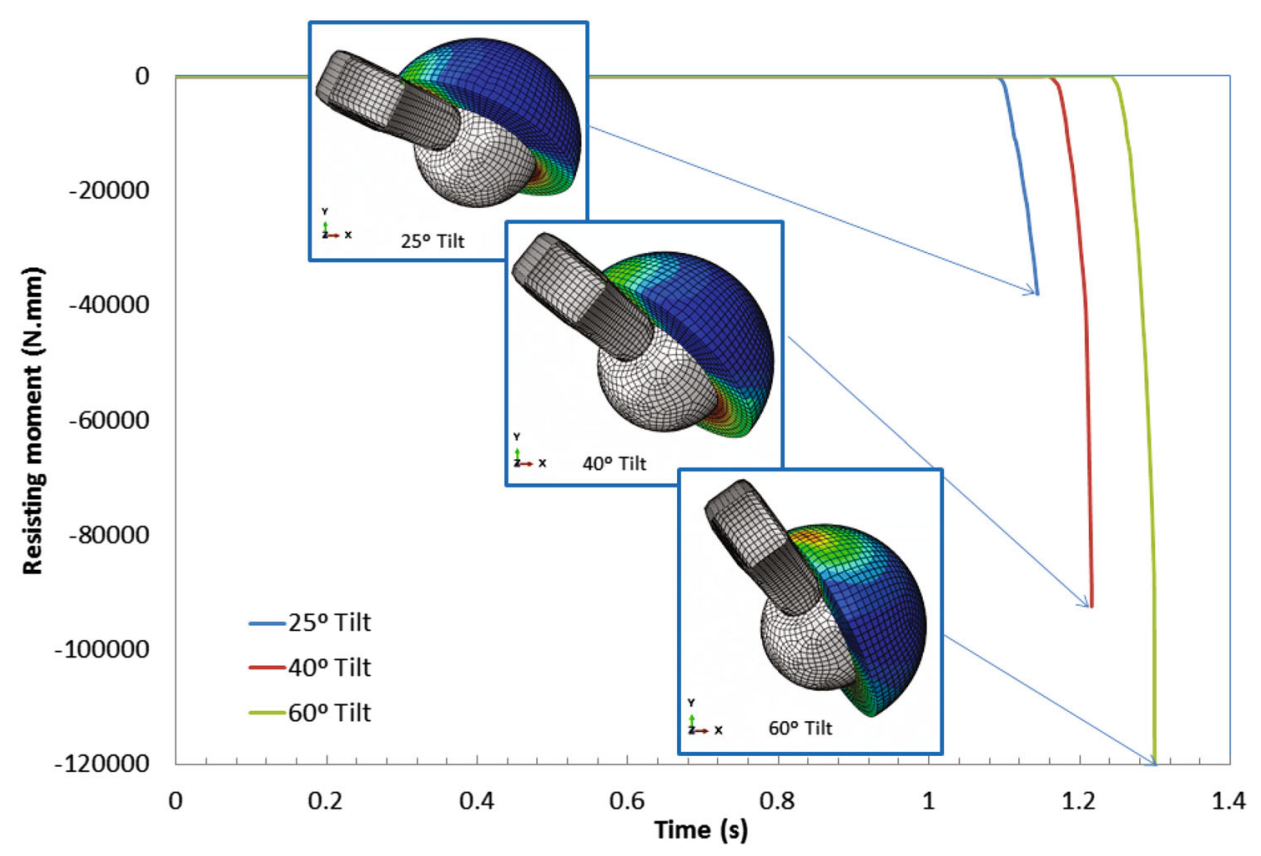

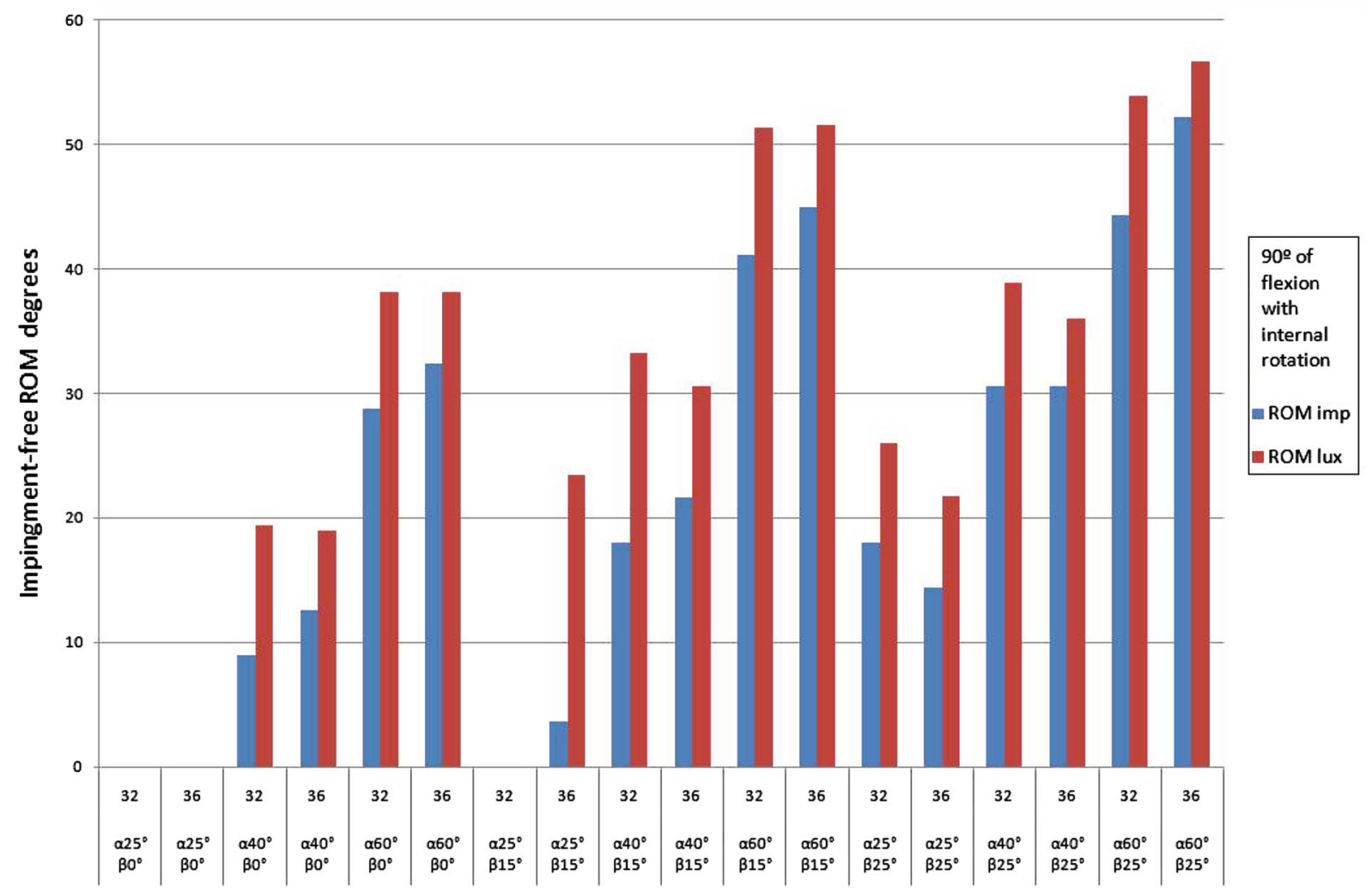

Fig. 5 Maximum impingement-free ROM for 32 and 36-mm head sizes

impingement site. The plots in Fig. 7 present the von Mises stress distribution on the inner surface of a smalldiameter liner $(28 \mathrm{~mm})$ and a large-diameter liner $(36 \mathrm{~mm})$ at the moment of dislocation for a cup position of $40^{\circ}$ abduction and $15^{\circ}$ anteversion. Stresses in the impingement site area were high for both models; however, for the larger head diameters, the stress decreased at the egress site. 
Fig. 6 Variation of RM for three head sizes $(28-36 \mathrm{~mm})$ with angle of flexion. Cup position is $25^{\circ}$ abduction and $0^{\circ}$ anteversion

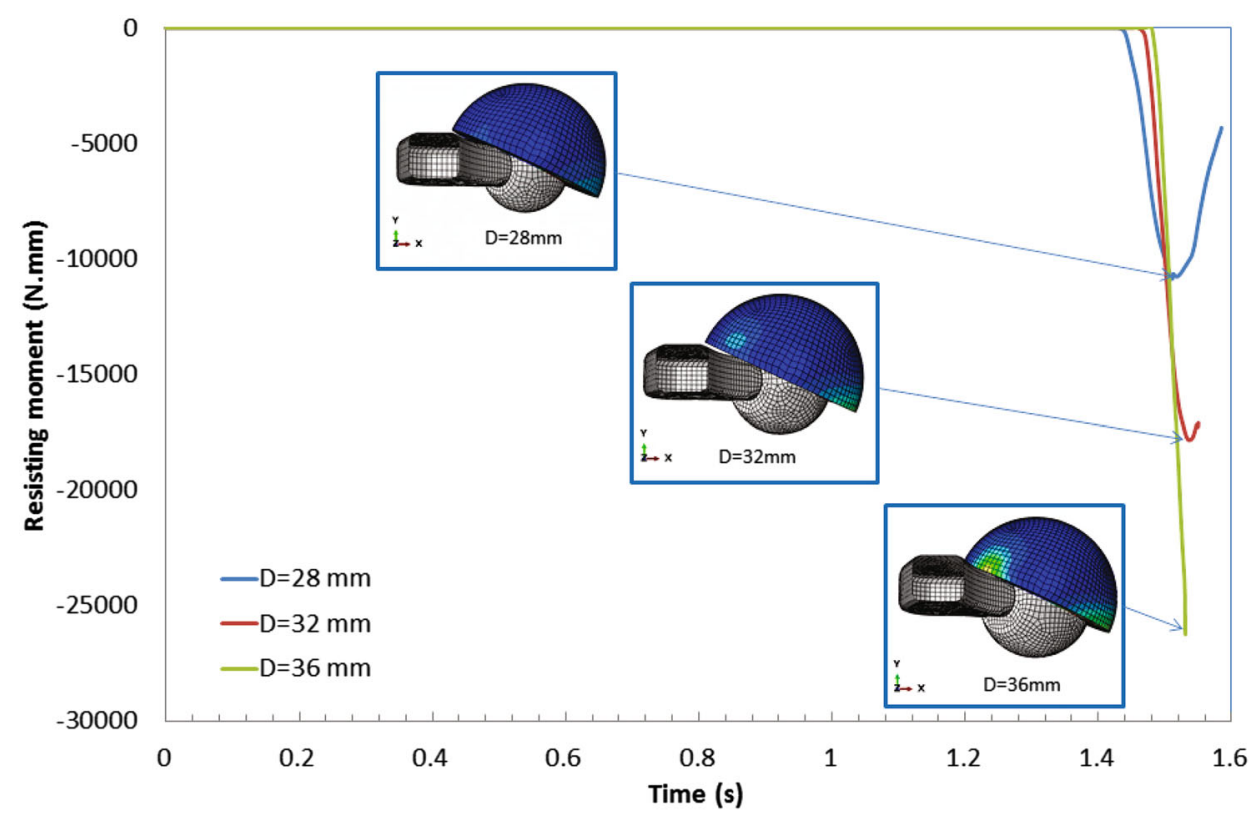

Fig. 7 Von Mises stress (MPa) plots of two implants with a 28-mm (left) and 36-mm (right) head sizes. At egress site, stress decreases for greater liner diameter at the moment of dislocation
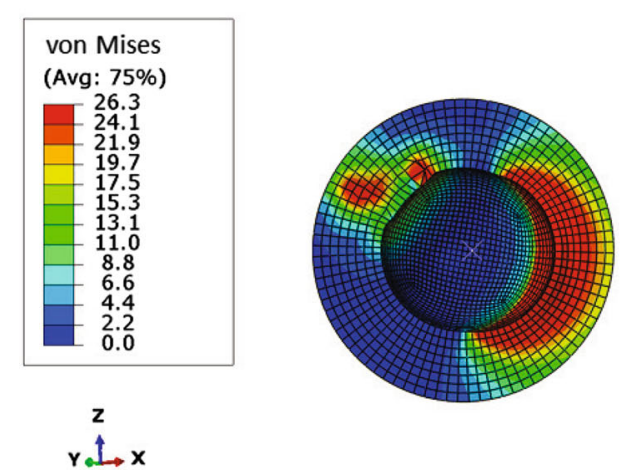

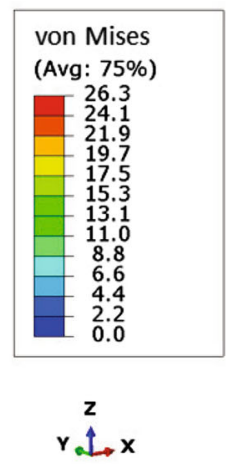

\section{Discussion}

Although it seems obvious that the orientation of the implant affects dislocation risk, some authors argue that that the opposite true $[22,31,32]$. Orientation is not the only factor, of course, because dislocations can also occur in properly oriented THRs; however, gross mal positioning will surely have some effect. Biedermann et al. [22] found that $93 \%$ of stable THRs in their series and, even more noteworthy, $67 \%$ of unstable THRs were within a "safe zone" for a cup placement of $15^{\circ} \pm 10^{\circ}$ anteversion and $45^{\circ} \pm 10^{\circ}$ abduction.

In their classic study, Lewinneck et al. [24] reported a $1.5 \%$ incidence of THR dislocation when the acetabulum component is placed within a "safe zone" of $15^{\circ} \pm 10^{\circ}$ anteversion and $40^{\circ} \pm 10^{\circ}$ abduction, while the incidence is $6.1 \%$ when it is not placed within these limits.

In the present FE study, it was found that the cup should be placed at $40^{\circ}-60^{\circ}$ abduction and $15^{\circ}-25^{\circ}$ anteversion. These values are similar to those reported by Kluess et al.
[15], who recommend an abduction of $45^{\circ}$ and an anteversion of $15^{\circ}-30^{\circ}$, and those reported by Pedersen et al. [16] who recommend at least $40^{\circ}$ abduction and $10^{\circ}$ anteversion. It seems that as we delve into the study of THR instability, anteversion becomes more important, and high values above $10^{\circ}-15^{\circ}$ are increasingly recommended. The most important and novel finding in this study is the recommendation of high anteversion angles and the finding of a delimited ROM.

In relation to head size, several publications have indicated the greater stability of larger heads $[1,33]$. In the experimental study of Bartz et al. [34], the primary mechanism of dislocation in THR with a $22-\mathrm{mm}$ head was impingement between prosthetic components; however, with a 32-mm head, the impingement occurred between anatomical structures, namely the lesser trochanter and the ischium. In our study, larger-diameter heads suffered impingement-dislocation with greater ROMs for a given cup position: they also exhibited a larger dislocation-free ROM, therefore indicating more stability. 
The improvement in stability with a larger femoral head diameter is also observed when analyzing the RM, which, as discussed above, increased as the diameter of the femoral head increased. A high RM implies more stability and more resistance to dislocation. These findings agree closely with those published by other authors [15, 17].

The stress distribution on the inner surface during the moment of impingement and dislocation was observed to be high for all head sizes at the impingement site. However, for larger head diameters, the stress decreased at the egress site. These findings suggest that larger heads can result in less wear of the polyethylene. This factor has been classically considered $[35,36]$ to be related with instability because it is associated with increased penetration of the femoral head into the acetabular component [6]. This fact favors prosthetic neck impingement, and the appearance of granulomas from polyethylene particles favors migration and even loosening of the acetabular component. Although wear was not analyzed in the present study, it could be simulated by incorporating a formulation based on the Archand wear law [37]. However, Wang et al. [38] found that large femoral heads cause more polyethylene wear than do smaller heads, when coupled with conventional UHMW-PE liners. Nevertheless, the low wear rate of newly developed cross-linked liners in combination with larger heads is promising. In low-wear bearing couples such as metal-on-metal and ceramic-on-ceramic couples, the use of larger femoral heads is preferred due to small contact stresses, which lead to a lower risk of mechanical failure. This experimental finding has not been corroborated by clinical practice with metal-on-metal couples [39]. Elkins et al. [40] also reported a similar conclusion. Manufacturing problems arise with larger heads, which release large amounts of chromium and cobalt particles that lead to failure of the implant: consequently, the use of resurfacing arthroplasties is currently under debate, and the use of some implants has been forbidden [41].

As stated previously, the etiology of prosthetic dislocation is multifactorial, and thus several design-related factors have been analyzed in this study (femoral head size, andante version and abduction of the acetabulum component position). Unfortunately, surgeon experience, patient activity levels, soft tissue compromise, and other non-design-related factors are confounding variables for determining dislocation propensity. Therefore, the main limitation of our study is the extrapolation of ours results. However, because component-on-component impingement is the most common factor and because the design and position of the implant can be controlled by the surgeon, we believe that these findings are relevant. The absence of capsule representation may lead to underestimated in vivo stability (and thus overestimated dislocation propensity) [8].
An additional limitation of our study is that the model did not incorporate bone-on-bone impingement, and hence, some additional cases of dislocation that would have occurred physically may have been overlooked. There is some evidence that ROM with larger head sizes is limited by bone-on-bone impingement, rather than that between prosthetic components. Elkins et al. [42] developed a dynamic FE model of total hip arthroplasty (THA) to analyze bone-on-bone versus prosthetic component impingement, concluding that prosthetic components are more likely to dislocate and have a greater propensity for causing damage to the implant compared to bone-on-bone impingement.

In our study, the outer acetabulum component remained constant at $52 \mathrm{~mm}$ for different femoral head sizes. This gives three different thickness of polyethylene liner $(8,10$, and $12 \mathrm{~mm}$ ) between the head and acetabulum component. Kluess et al. [15] used a constant thickness of $7 \mathrm{~mm}$. Changing the acetabulum thickness did not affect the ROM but slightly affected the stress distribution on the acetabular component. In any case, as the FE model developed here is a parametric model, incorporation of the patient's bone structure could clearly lead to improved results. In the future, a parametrized bone structure should be incorporated to achieve a patient-specific approach. Additionally, future research should focus on the effect of the femoral offset, which may improve flexion and internal rotation [11].

\section{Conclusion}

The "safe zone" of movement for impingement and dislocation avoidance in THR predicted by the proposed FE model is $40^{\circ}-60^{\circ}$ abduction and $15^{\circ}-25^{\circ}$ anteversion. It is especially critical that the anteversion does not fall to $10^{\circ}$ $15^{\circ}$. Large heads have a greater stability and a lower polyethylene wear rate in comparison to those of smaller heads. The progression of the RM is valid for describing dislocation stability in FE studies. Therefore, despite previous limitations, the proposed parametric 3D FE model can be used to predict dislocation stability under a wide range of conditions.

Acknowledgements The authors gratefully acknowledge the research support of the Spanish Ministry of Science and Technology through Research Project DPI2014-53401-C2-1-R and the SECOT Foundation.

\section{Compliance with Ethical Statements}

Conflict of interest The authors declare that they have no conflicts of interest.

Ethical Approval This article does not contain any studies performed on human participants or animals. 


\section{References}

1. Berry, D. J., Von Knoch, M., Schleck, C. D., \& Harmsen, W. S. (2005). Effect of femoral head diameter and operative approach on risk of dislocation after primary total hip arthroplasty. Journal of Bone and Joint Surgery. American Volume, 87, 245-263.

2. Homesley, H. D., Minnich, J. M., Parvizi, J., \& Hozack, W. J. (2004). Total hip arthroplasty revision: A decade of change. American Journal of Orthopedics, 33, 338-392.

3. Lawton, R. L., \& Morrey, B. F. (2004). Dislocation after longnecked total hip arthroplasty. Clinical Orthopaedics and Related Research, 422, 164-166.

4. Padgett, D. E., \& Warashina, H. (2004). The unstable total hip replacement. Clinical Orthopaedics and Related Research, 420, 72-79.

5. Parvizi, J., Kim, K.-I., Goldberg, G., Mallo, G., \& Hozack, W. J. (2006). Recurrent instability after total hip arthroplasty. Beware of subtle component malpositioning. Clinical Orthopaedics and Related Research, 447, 60-65.

6. Lin, H. C., Chi, W. M., Ho, Y. J., \& Chen, J. H. (2013). Effects of design parameters of total hip components on the impingement angle and determination of the preferred liner skirt shape with an adequate oscillation angle. Medical \& Biological Engineering \& Computing, 51(4), 397-404.

7. He, R. X., Yan, S. G., Wu, L. D., Wang, X. D., \& Dai, X. S. (2007). Position of the prosthesis and the incidence of dislocation following total hip replacement. Chinese Medical Journal, 120(13), 1140-1144.

8. Nadzadi, M. E., Pedersen, D. R., Callaghan, J. J., \& Brown, T. D. (2002). Effects of acetabular component orientation on dislocation propensity for small-head-size total hip arthroplasty. Clinical Biomechanics (Bristol, Avon), 17, 32-40.

9. Bader, R., Steinhauser, E., Zimmermann, S., Mittelmeier, W., Scholz, R., \& Busch, R. (2004). Differences between the wear couples metal-on-polyethylene and ceramic-on-ceramic in the stability against dislocation of total hip replacement. Journal of Materials Science Materials in Medicine, 15, 711-718.

10. Burroughs, B. R., Hallstrom, B., Golladay, G. J., Hoeffel, D., \& Harris, W. H. (2005). Range of motion and stability in total hip arthroplasty with 28-, 32-, 38-, and 44-mm femoral head sizes. Journal of Arthroplasty, 20(1), 11-19.

11. Matsushita, A., Nakashima, Y., Jingushi, S., Yamamoto, T., Kuraoka, A., \& Iwamoto, Y. (2009). Effects of the femoral offset and the head size on the safe range of motion in total hip arthroplasty. Journal of Arthroplasty, 24(4), 646-651.

12. Sun, H., Inaoka, H., Fukuoka, Y., Masuda, T., Ishida, A., \& Morita, S. (2007). Range of motion measurement of an artificial hip joint using CT images. Medical \& Biological Engineering \& Computing, 45(12), 1229-1235.

13. Bachtar, F., Chen, X., \& Hisada, T. (2006). Finite element contact analysis of the hip joint. Medical \& Biological Engineering \& Computing, 44(8), 643-651.

14. Hübsch, P. F., Middleton, J., Meroi, E. A., \& Natali, A. N. (1995). Adaptive finite-element approach for analysis of bone/ prosthesis interaction. Medical \& Biological Engineering \& Computing, 33(1), 33-37.

15. Kluess, D., Martin, H., Mittelmeier, W., Schmitz, K. P., \& Bader, R. (2007). Influence of femoral head size on impingement, dislocation and stress distribution in total hip replacement. Medical Engineering \& Physics, 29(4), 465-471.

16. Pedersen, D. R., Callaghan, J. J., \& Brown, T. D. (2005). Activitydependence of the "safe zone" for impingement versus dislocation avoidance. Medical Engineering \& Physics, 27(4), 323-328.

17. Scifert, C. E., Brown, T. D., Pedersen, D. R., \& Callaghan, J. J. (1998). A finite element analysis of factors influencing total hip dislocation. Clinical Orthopaedics and Related Research, 335, $152-162$

18. Scifert, C. E., Brown, T. D., Pedersen, D. R., Heiner, A. D., \& Callaghan, J. J. (1999). Development and physical validation of a finite element model of total hip dislocation. Computer Methods in Biomechanics and Biomedical Engineering, 2(2), 139-147.

19. Scifert, C. E. (1999). A finite element investigation into the biomechanics of total artificial hip dislocation $(P h D)$. Iowa City: Biomedical Engineering, University of Iowa.

20. Choy, G. G., Roe, J. A., Whitehouse, S. L., Cashman, K. S., \& Crawford, R. W. (2013). Exeter short stems compared with standard length Exeter stems: Experience from the Australian Orthopaedic Association National Joint Replacement Registry. Journal of Arthroplasty, 28(1), 103-109.

21. Gava, R., Hernández Vaquero, D., Suárez Vázquez, A., de Cima, Suárez M., \& Cervero, J. (2005). Influencia de la vía de abordaje y de la posición de la cúpula acetabular en la luxación de la artroplastia total de cadera. Estudio caso-control. Revista Española de Cirugía Osteoarticular, 40, 134-140.

22. Biedermann, R., Tonnin, A., Krismer, M., Rachbauer, F., Eibl, G., \& Stöckl, B. (2005). Reducing the risk of dislocation after total hip arthroplasty. The effect of orientation of the acetabular component. Journal of Bone and Joint Surgery. British Volume, 87, 762-769.

23. Elkins, J. M., O’Brien, M. K., Stroud, N. J., Pedersen, D. R., Callaghan, J. J., \& Brown, T. D. (2011). Hard-on-hard total hip impingement causes extreme contact stress concentrations. Clinical Orthopaedics and Related Research, 469, 454-463.

24. Lewinnek, G. E., Lewis, J. L., Tarr, R., Compere, C. L., \& Zimmerman, J. R. (1978). Dislocation after total hip replacement arthroplasties. Journal of Bone and Joint Surgery. American Volume, 60, 217-220.

25. Morrey, B. F. (1992). Instability after total hip arthroplasty. Orthopedic Clinics of North America, 23, 237-248.

26. Kurtz, S. M., Pruitt, L., Jewett, C. W., Crawford, R. P., Crane, D. J., \& Edidin, A. A. (1998). The yielding, plastic flow, and fracture behavior of ultra-high molecular weight polyethylene used in total joint replacements. Biomaterials, 19(21), 1989-2003.

27. Voigt, C., Klöhn, C., Bader, R., von Salis-Soglio, G., \& Scholz, R. (2007). Finite element analysis of shear stresses at the implantbone interface of an acetabular press-fit cup during impingment. Biomedizinische Technik, 52(2), 208-215.

28. Hernández, Vaquero D. (1997). La Cadera (1st ed.). Madrid: Médica Panamericana.

29. Kapandji, A. I. (2010). Fisiología articular: Cadera, rodilla, tobillo, pie, bóveda plantar, marcha, vol 2 (6th ed.). Madrid: Médica Panamericana.

30. Yoshime, F., \& Ginbayashi, K. (2002). A mathematical formula to calculate the theoretical range of motion for total hip replacement. Journal of Biomechanics, 35, 989-993.

31. Caeiro, J. R., Riba, J., \& Gomar, F. (2011). Incidencia y factores de riesgo de luxación tras artroplastias totales de cadera con sistema acetabular de cerámica. Revista Española de Cirugía Ortopédica y Traumatología, 55, 437-445.

32. Paterno, S. A., Lachiewicz, P. F., \& Kelley, S. S. (1997). The influence of patient-related factors and the position of the acetabular component on the rate of dislocation after total hip replacement. Journal of Bone and Joint Surgery. American Volume, 79, 1202-1210.

33. Amlie, E., HØvik, Ø., \& Reikerås, O. (2010). Dislocation after total hip arthroplasty with 28 and $32 \mathrm{~mm}$ femoral head. Journal of Orthopaedics and Traumatology, 11, 111-115.

34. Bartz, R. L., Noble, P. C., Kadakia, N. R., \& Tullos, H. S. (2000). The effect of femoral component head size on posterior dislocation of the artificial hip joint. Journal of Bone and Joint Surgery. American Volume, 82, 1300-1307. 
35. Khatod, M., Barber, T., Paxton, E., Namba, R., \& Fithian, D. (2006). An analysis of the risk of hip dislocation with a contemporary total joint registry. Clinical Orthopaedics, 447, 19-23.

36. Scifert, C. F., Noble, P. C., Brown, T. D., Bartz, R. L., Kadakia, N., Sugano, N., et al. (2001). Experimental and computational simulation of total hip arthroplasty dislocation. Orthopedic Clinics of North America, 32(4), 553-567.

37. Kruger, K. M., Tikekar, N. M., Heiner, A. D., Baer, T. E., Lannutti, J. J., Callaghan, J. J., et al. (2014). A novel formulation for scratch-based wear modelling in total hip arthroplasty. Computer Methods in Biomechanics and Biomedical Engineering, 17(11), 1227-1236.

38. Wang, A., Essner, A., \& Klein, R. (2001). Effect of contact stress on friction and wear of ultra-high molecular weight polyethylene in total hip replacement. Proceedings of the Institution of Mechanical Engineers, 215, 133-139.
39. Haddad, F. S., \& Konan, S. (2012). Current controversies in hip surgery. Journal of Bone and Joint Surgery. British Volume, 94(3), 297-301.

40. Elkins, J. M., Kruger, K. M., Pedersen, D. R., Callaghan, J. J., \& Brown, T. D. (2012). Edge-loading severity as a function of cup lip radius in metal-on-metal total hips-a finite element analysis. Journal of Orthopaedic Research, 30, 169-177.

41. Langton, D. J., Joyce, T. J., Jameson, S. S., et al. (2011). Adverse reaction to metal debris following hip resurfacing: The influence of component type, orientation and volumetric wear. Journal of Bone and Joint Surgery. British Volume, 93(2), 164-171.

42. Elkins, J. M., Pedersen, D. R., Callaghan, J. J., \& Brown, T. D. (2012). Bone-on-bone versus hardware impingement in total hips: A biomechanical study. Iowa Orthopaedic Journal, 32, 17-21. 